\title{
Hirayama disease (monomelic amyotrophy) clinically confused for carpal tunnel syndrome
}

This article was published in the following Dove Press journal:

Neuropsychiatric Disease and Treatment

22 May 2017

Number of times this article has been viewed

Halil Ay

Neurology Department of Medical Faculty, Harran University, Sanliurfa, Turkey
Correspondence: Halil Ay Neurology Department of Medical Faculty, Harran University, SanliurfaMardin Highway 18th km, 63050,

Sanliurfa, Turkey

Tel+905306934206

Email ayhalil27@hotmail.com

\begin{abstract}
Hirayama disease (HD) is a rare motor neuron disorder that involves a single upper extremity. It is clinically characterized by weakness and atrophy of the muscles of the hand and forearm. This article presents a 19-year-old woman who visited the orthopedics outpatient clinic with weakness and atrophy in her right hand and was clinically diagnosed with advanced stage carpal tunnel syndrome and scheduled for surgical intervention; she was later diagnosed with HD by an electrophysiological study. As a result, it has been found that a careful electrophysiological study and neurological examination can be used to diagnose HD. In this way, advanced stage carpal tunnel syndrome will be ruled out and patients will be spared from an unnecessary surgical operation.

Keywords: Hirayama disease, carpal tunnel syndrome, electroneuromyography, motor neuron disorder, thenar atrophy, compound muscular action potential
\end{abstract}

\section{Introduction}

Hirayama disease (HD), also known as monomelic amyotrophy (MA), is a rare motor neuron disorder that involves a single upper extremity. ${ }^{1}$ In 1959, Hirayama et al first described this disease, which reportedly lacks clinical signs compatible with any of the previously recognized degenerative disorders or disorders causing progressive muscular dystrophy. ${ }^{2}$

The age of onset of the disease ranges between 20 and 35 years, and it is more common in men. It is clinically characterized by weakness and atrophy of the muscles of hand and forearm. ${ }^{3}$ The disease is limited to motor neuron involvement affecting upper extremity, and lower extremity, bulbar, and sensory involvement are absent., In some cases, muscle weakness becomes prominent in cold weather (cold paresis). Affected persons complain about their weakness being exaggerated in cold weather and resolved in warm weather. Hence, they typically notice their disease in winter months. Rarely, the disease may be accompanied by hyperhidrosis and abnormal sympathetic skin response. Although its etiology is unknown, theories have been put forth that it occurs secondary to chronic compression of spinal cord or atopy. ${ }^{6}$

This report presents a 19-year-old woman who visited the orthopedics outpatient clinic with weakness and atrophy in her right hand and was clinically diagnosed with advanced stage carpal tunnel syndrome and scheduled for surgical intervention; she was later diagnosed with HD by an electrophysiological study. Before attempting to prepare the paper, a written informed consent to have the case details and any accompanying images published was obtained from the patient.

\section{Case report}

A 19-year-old woman who presented to the orthopedics outpatient clinic with weakness and atrophy in her right hand was diagnosed with advanced stage carpal 
tunnel syndrome and recommended surgery. She was then referred to the electrophysiology laboratory of the hospital's neurology department for electroneuromyography (ENMG). She stated that her symptoms had begun 2 years ago; she occasionally had numbness and chilling sensation in her right arm; and she had long been unable to carry anything in her right hand. Her past and family history was unremarkable. Her physical examination was also normal except for neurological examination which revealed atrophic appearance of the right hand (Figures 1 and 2) and a muscle strength of $4 / 5$ in the distal part of the right arm. It was also noted that the distal interphalangeal joint of the first finger of the right hand had a muscle strength of $1 / 5$ and the proximal one had a muscle strength of $4 / 5$. Muscle strength was $2 / 5$ in the distal and proximal interphalangeal joints of the second finger. Thenar atrophy of the right hand was also found. The

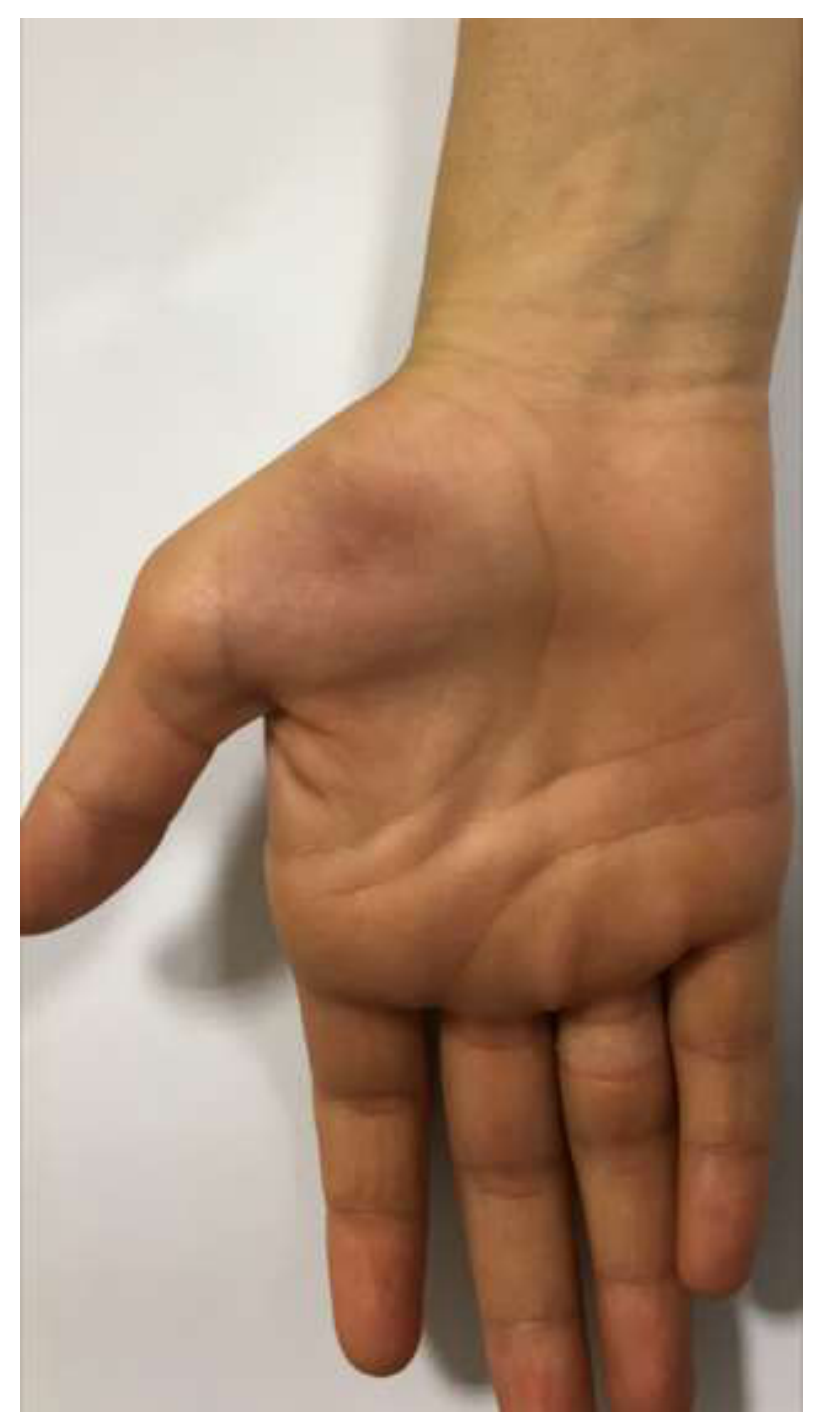

Figure I Palm view: pronounced thenar atrophy of the right hand.

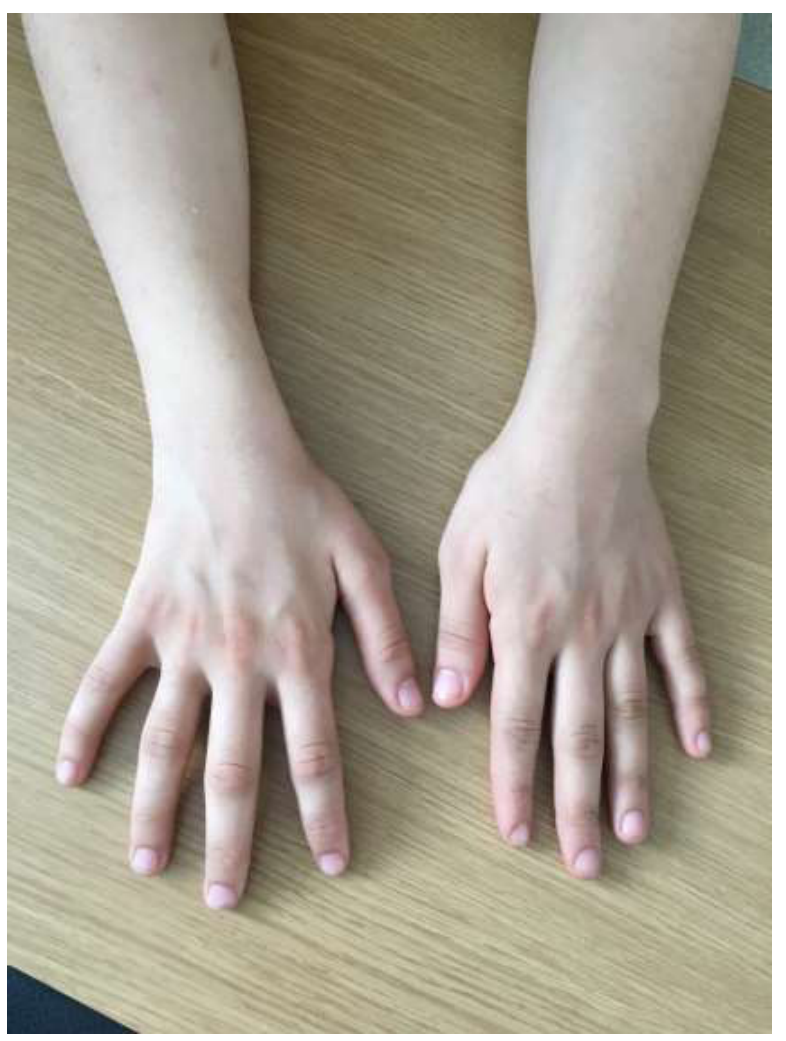

Figure 2 Dorsal view of both hands: pronounced thenar atrophy of the right hand.

wrist circumference measured $5 \mathrm{~cm}$ proximal to the wrist was $15 \mathrm{~cm}$ on the right side and $16 \mathrm{~cm}$ on the left side. The arm circumference measured $10 \mathrm{~cm}$ proximal to the elbow was $26 \mathrm{~cm}$ on the right side and $26.5 \mathrm{~cm}$ on the left side. All biochemical and blood count parameters were within the normal range. Thyroid function tests and creatine kinase levels were also normal. Cranial and cervical vertebral magnetic resonance imaging (MRI) studies performed at an outside center were normal.

An ENMG was performed, which demonstrated an absent right median and ulnar nerve compound muscular action potential (CMAP) at the motor conduction study. The sensory conduction study revealed normal sensory action potential (SAP) conduction velocities and amplitudes in the right median nerve, right ulnar nerve, right radial nerve, right lateral antebrachial cutaneous nerve (right median nerve second finger SAP amplitude $56.6 \mu \mathrm{V}$, conduction velocity $63.8 \mathrm{~m} / \mathrm{s}$; right median nerve third finger SAP amplitude $34.7 \mu \mathrm{V}$, conduction velocity $59.3 \mathrm{~m} / \mathrm{s}$; right ulnar nerve fifth finger amplitude $12.1 \mu \mathrm{V}$, conduction velocity $56.3 \mathrm{~m} / \mathrm{s}$; right radial nerve amplitude $31.2 \mu \mathrm{V}$, conduction velocity $59 \mathrm{~m} / \mathrm{s}$; right lateral antebrachial cutaneous nerve amplitude $11.1 \mu \mathrm{V}$, conduction velocity $66.7 \mathrm{~m} / \mathrm{s}$ ). A needle ENMG recorded very large amplitude single oscillation pattern and 
diffuse spontaneous denervation potentials (positive sharp waves and fibrillation potentials) in the right first dorsal interosseous muscle, right abductor digiti minimi muscle, and right abductor pollicis brevis muscle. Electrophysiological study of forearm muscles was normal. HD was diagnosed as the definitive diagnosis.

\section{Discussion}

HD affects men more commonly than women, and the first symptoms appear in the 20s. HD is limited to a single extremity such as an arm or hand rather than legs. ${ }^{7}$ The age of the patient of the present study was consistent with the literature reports although her gender was female, being in a less affected group. Nalini et al, in a 190-patient study, reported only one case of familial HD. ${ }^{8}$ No family member of the patient had this disease, and thus he was considered a sporadic case. The common clinical symptoms of the disease which are present in $>80 \%$ of the affected persons include cold paresis and irregular tremor in finger extension (minipolymyoclonus)., ${ }^{9,10}$ The patient had cold paresis but lacked irregular tremor or involuntary movements.

HD is a condition with insidious onset and limits itself with atrophy and weakness in hand and forearm. ${ }^{11}$ The patient in the present study had no prominent atrophy and weakness in her right upper extremity and forearm but had prominent thenar atrophy and weakness in hand muscles, making the orthopedic surgeon consider advanced stage carpal tunnel syndrome. In the latter, the addition of worsened localized demyelination and axonal degeneration leads to muscle paresis and atrophy as well as skin hypoesthesia and anesthesia. It is common that as the intensity of neurological signs increase, pain and paresthesia are gradually alleviated but thenar atrophy becomes more prominent. In this patient, a more prominent atrophy in the thenar region compared to the hypothenar region and the absence of pain, which were coupled with the absence of electrophysiological tests, led the orthopedic surgeon to diagnose advanced stage carpal tunnel syndrome, a condition which is common.

Although hyperhidrosis and abnormal sympathetic skin responses have been reported in some studies, this patient lacked excess perspiration, and sympathetic skin responses were not studied.

Nerve conduction tests have been found normal in most patients with HD. ${ }^{12}$ Nevertheless, atypical cases have also been reported, which were characterized by slowed conduction and reduced CMAP amplitudes. Hamano et al reported reduced conduction velocity and reduced CMAP amplitudes in the affected extremity. ${ }^{13} \mathrm{CMAP}$ could not be obtained from the motor fibers of the right median and ulnar nerves in the nerve conduction study.

ENMG yields a typical neurogenic response in atrophic muscles, suggesting anterior horn involvement. In this patient, very large amplitude single oscillation pattern and diffuse spontaneous denervation potentials (positive sharp waves and fibrillation potentials) were detected, suggesting anterior horn cellular involvement in the right hand where atrophy was observed (in right first dorsal interosseal muscle, right abductor digiti minimi muscle, and right abductor pollicis brevis muscle).

A report in the literature has identified intrinsic spinal cord pathologies in cervical MRI in some cases. ${ }^{14}$ This patient had normal cervical MRI examination.

Although similar distal atrophy of forearm and hand can be observed in the early stages of amyotrophic lateral sclerosis, there are typical fasciculations in the upper aspect of the arm during rest. ${ }^{15}$ The patient did not have similar fasciculations.

In conclusion, HD should be definitely considered in the differential diagnosis of advanced stage carpal tunnel syndrome in a young person presenting with weakness in hand muscles and a predominant thenar atrophy in a single upper extremity. A careful electrophysiological study and neurological examination can make the diagnosis of HD. In this way, advanced stage carpal tunnel syndrome will be ruled out and patients will be spared from an unnecessary surgical operation.

\section{Disclosure}

The author reports no conflicts of interest in this work.

\section{References}

1. Fetoni V, Briem E, Carrara F, Mora M, Zeviani M. Monomelic amyotrophy associated with the 7472insC mutation in the mtDNA tRNA gene. Neuromuscul Disord. 2004;14:723-726.

2. Hirayama K, Toyokura Y, Tsubaki T. Juvenile muscular atrophy of unilateral upper extremity: a new clinical entity. Psychiatr Neurol Jpn. 1959;61:2190-2198.

3. Emre M. Fundamental Book of Neurology. 1st ed. Ankara: Günes Publications; 2013. Turkish.

4. Rowin J, Meriggioli MN, Cochran EJ. Monomelic amyotrophy with late progression. Neuromuscul Disord. 2001;11:305-308.

5. Sullivan O, McLeod J. Distal chronic spinal muscular atrophy involving the hands. J Neurol Neurosurg Psychiatry. 1978;41:653-658.

6. Nalini A, Lokesh E, Ratnavalli E. Familial monomelic amyotrophy: a case report from India. J Neurol Sci. 2004;220:95-98.

7. Rowland LP, Pedley TA. Merritt's Neurology. Turkish edition, 12th edn; Günes Publications, Ankara, Turkey, 2012.

8. Nalini A, Lokesh E, Ratnavalli E. Familial monomelic amyotrophy: a case report from India. J Neurol Sci. 2004;220:95-98.

9. Sawai S, Misawa S, Kanai K, et al. Altered axonal excitability properties in juvenile muscular atrophy of distal upper extremity (Hirayama disease). Clin Neurophysiol. 2011;122:205-209.

10. Zhou B, Chen L, Fan D, Zhou D. Clinical features of Hirayama disease in mainland China. Amyotroph Lateral Scler. 2010;11:133-139. 
11. Kiernan MC, Lethlean AK, Blum PW. Monomelic amyotrophy: non progressive atrophy of the upper limb. J Clin Neurosci. 1999;6:353-355.

12. Gourie Devi M, Nalini A. Long term follow-up of 44 patients with brachial monomelic amyotrophy. Acta Neurol Scand. 2003;107:215-220.

13. Hamano T, Mutoh T, Hirayama M, et al. MRI findings of benign monomelic amyotrophy of lower limb. J Neurol Sci. 1999;165: $184-187$.
14. Schroder R, Keller E, Flacke S, et al. MRI findings in Hirayama's disease: flexion induced cervical myelopathy or intrinsic motor neuron disease? J Neurol. 1999;246:1069-1074.

15. Tunçbay T, Tunçbay E. Nöromüsküler Hastalıklar. Đzmir: Ege Üniversitesi Basım Evi; 2000:136-140.

\section{Publish your work in this journal}

Neuropsychiatric Disease and Treatment is an international, peerreviewed journal of clinical therapeutics and pharmacology focusing on concise rapid reporting of clinical or pre-clinical studies on a range of neuropsychiatric and neurological disorders. This journal is indexed on PubMed Central, the 'PsycINFO' database and CAS,

and is the official journal of The International Neuropsychiatric Association (INA). The manuscript management system is completely online and includes a very quick and fair peer-review system, which is all easy to use. Visit http://www.dovepress.com/testimonials.php to read real quotes from published authors. 